\title{
Improvements in the supply chain, a company's personal hygiene products to reduce inventory levels
}

\author{
Daniel Sarcos \\ University of California, United States of America \\ danielsarcos33@gmail.com
}

\begin{abstract}
Objectives: Improve a company's supply chain of personal hygiene products to reduce inventory levels and maintain high levels of service, in order to increase sales, reduce costs and improve cash flow.

Methods/Statistical analysis: High levels of inventory were identified through the analysis of reports and interviews with staff. Subsequently, redistribution and inventory forecasting processes were designed.

Findings: The inventory is reduced by more than five hundred thousand dollars.

Application/Improvements: These results allow to maintain the competitiveness of the company under study and even to improve supply chains of other brands to increase the margin of profit of this one.

Keywords: Supply chain, service, inventory, inventory redistribution, finished product.
\end{abstract}

\section{INTRODUCTION}

In order to achieve the reduction of costs raised by the top executives of the company, which amount to ten (10) billion dollars by 2016, the company has set goals based on the Key Performance Indicators (ICD) which must be reached year after year in each category. Personal hygiene products, being one of the largest brands of the company, has one of the major challenges for the reduction of inventory, which requires special attention in this brand ${ }^{1,2}$.

That is why it is necessary to diagnose and study the entire supply chain of personal hygiene products, to identify key factors for its improvement and to design and implement improvement proposals that allow the reduction of inventories, maintenance of levels Service and cost reduction in the category.

Likewise, improvements achieved will reduce storage costs and capital costs related to low turnover inventories, thus increasing the brand's competitiveness and profit margins.

\section{THEORETICAL FOUNDATION}

As shown in Figure 1 supply chain or "supply chain" (SC) encompasses all activities associated with the flow and transformation of goods and associated information from the fa of raw materials to the thin user 1. It is essentially a set of connected suppliers and customers; where each customer is in turn the next provider organization "downstream" until the finished product reaches the end user ${ }^{2}$.

Today, it seems evident the obsolescence of the industrial paradigm based on optimizing the processes of the supply chain as if they were isolated functions aimed outside $r$ optimizes its efficiency and stability. Companies must evolve from that endogenic industrial approach based on the internal efficiency of processes oriented on the added value given to customers with an overview of the chain paradigm ${ }^{4}$. 


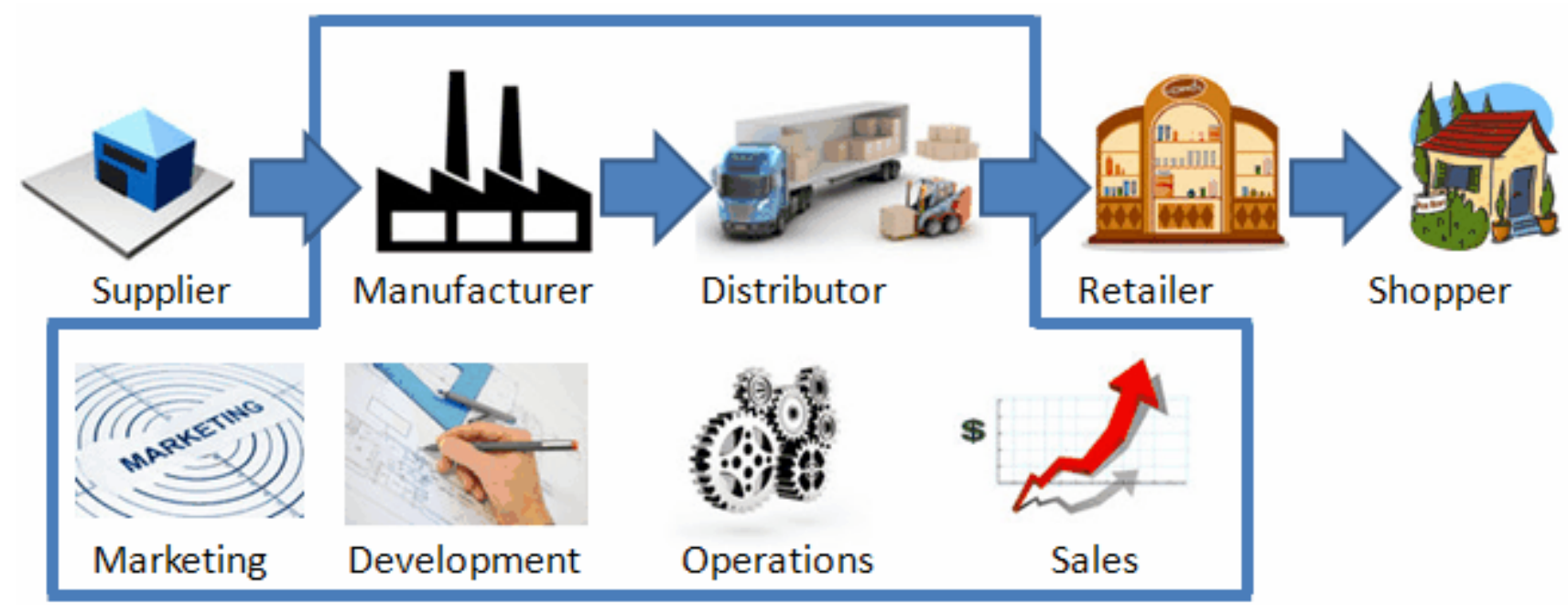

Fig1. Traditional supply chain ${ }^{3}$

The factor that catalyzes all these changes is undoubtedly the increase in an increasingly demanding and personalized customer demand. In addition, global competition stimulates this change and force manufacturers to find new ways to produce more in line with the changing needs and personalized market, the same time keep the costs as low as possible. All this is forcing companies to find new ways of collaboration to improve the integration and synchronization of the various functions and stages of the supply chain of their products 5 .

Increasingly, companies around the world are flocking to a supply chain as the latest methodology to reduce costs, increase customer satisfaction, better use of existing assets and build new revenue. The management of the supply chain (Supply Chain Management) is the integration of these activities through improved chain to gain a sustainable competitive advantage relationships. In this definition, the management of the supply chain includes management information systems, procurement and purchasing, production scheduling, order processing, inventory management, storage, service customer service and after sales. It is a management approach that proposes the integration and coordination of all key business processes ranging from the end user and the initial suppliers is, in order to create and between gar value to the end user, in finished products and services ${ }^{6}$.

\section{METHODOLOGY}

The study was conducted on the Finished Products Supply Chain (CSPT) of personal care products in Europe, the Middle East and Africa (EMOA). ${ }^{3,7,8,9,10,11,12,13,14,15}$

In a first phase of diagnosis, it is sought to understand the current situation of CSPT in EMOA. For this purpose it is necessary to understand the operation of the company, the supply chain and the information systems that are used in the Department of Supply Chain Planning department. Likewise, it is necessary to understand and analyze the reports and processes used for the management and supervision of the supply chain. Then, factors and opportunities are identified in the supply chain to improve key performance indicators (DCI).

Once the previous stage is concluded, group meetings are scheduled with the experts and in charge of the approval, where the feasibility of each proposal is determined and the implementation times are redefined as well as the measures taken to achieve the improvements. These meetings involve all those who may be related to the project, especially those who are directly involved in the implementation. Once the feedback from the parties has been received, the previous stage is repeated where the proposals are generated to modify and adjust them according to the given requirements. 
This cycle is repeated until the round of discussions with the experts and employees involved creates a consensus and decides what and how to apply them, especially considering that there are time constraints and resource constraints. Finally the proposals are implemented.

\section{RESULTS}

When considering the entire EMOA region, the levels of inventories measured in monetary units reach 173 million by February 2012, from which almost 67 million correspond to the Low Utility Inventory (IBU). Table 1 shows the IBU values, sectioned according to the type of inventory.

Table 1. Levels of (IBU) in monetary units (UM) of the Chain of Supplies of Shavers and Blades

\begin{tabular}{|c|c|c|c|c|c|c|}
\hline & $\begin{array}{l}\text { IBU Total } \\
\text { Inventory }\end{array}$ & $\begin{array}{l}\text { Dead (IM) } \\
\text { Inventory }\end{array}$ & $\begin{array}{c}\text { Inventory Excess } \\
\text { (IE) }\end{array}$ & $\begin{array}{l}\text { Inactive Orange } \\
\text { (IN) }\end{array}$ & $\begin{array}{l}\text { Inactive Red } \\
\text { (IR) }\end{array}$ & Total Inventory \\
\hline \multirow{2}{*}{$\begin{array}{l}\text { January- } \\
2012\end{array}$} & $64,660,139.87$ & $38,443,760.90$ & $16,888,027.79$ & $6,906,222.66$ & $2,422,128.53$ & \multirow[t]{2}{*}{$179,288,062.80$} \\
\hline & $36.1 \%$ & $21.4 \%$ & $9.4 \%$ & $3.9 \%$ & $1.4 \%$ & \\
\hline \multirow{2}{*}{$\begin{array}{l}\text { February- } \\
2012\end{array}$} & $66,803,834.48$ & $41,913,073.89$ & $15,515,921.04$ & $6,796,542.60$ & $2,578,296.95$ & \multirow[t]{2}{*}{$173,746,068.29$} \\
\hline & $38.4 \%$ & $24.1 \%$ & $8.9 \%$ & $3.9 \%$ & $1.5 \%$ & \\
\hline Goal & $33 \%$ & $15 \%$ & $10 \%$ & $6 \%$ & $2 \%$ & \\
\hline
\end{tabular}

As can be seen in Table 1, the established target of IBU has not been reached, and it is clear that this is specifically due to the large amount of Dead Inventory (IM) approaching almost a quarter of the total inventory for the month Of February of 2012.

This large amount of dead inventory can indicate excessive levels of Security Inventory (IS), as well as high levels of IE. When discussing this information in business interviews, it is determined that the observation is correct and that the Chain of Supplies of Shakers and Leaflet has high levels of IS and IE.

After the interview and data analysis, the implementation priorities are $8,9,10,11,16,17,18,19,20,21,22,23,24,25,26,27$ :

1. High levels of Excess Inventory: it is considered the highest priority because it can be executed in the short term and contributes to significantly improve the Key Performance Indicators (DCI).

2. High levels of Inactive Inventory: it is considered of medium priority since Inactive Inventory levels are much lower compared to IE.

3. Cyclical Inventory Levels in Poorly Scheduled Market Development Organization (ODM): considered as a third priority since the correction of this factor cannot be done in the short term.

4. Poorly designed inventory policies: considered as the last priority because they cannot be executed in the short term and the reduction of (IS) levels are not of great impact.

\section{Pilot Tests of the Redistribution Process.}

This process applies to the Chain of Supplies of Shavers and Blades as pilot phase.

The first tests were carried out in the MDGs of Italy, Southeastern Europe, the United Kingdom and France, in addition to an additional redistribution to the Lodz Customization Center.

It also maintains continuous contact with the executioners to verify the amount of additional expenses generated due to the use of this process or if it is necessary to change any part thereof.

During the pilot tests of the Redistribution Process the following results were obtained (table 2): 
Table 2. Results of Redistributions

\begin{tabular}{|c|c|c|c|c|}
\hline Place & $\begin{array}{l}\text { Redistributed } \\
\text { Pallets }\end{array}$ & Redistribution Value & Pallets sent to re-packing & $\begin{array}{c}\text { Total Execution Time } \\
\text { (weeks) }\end{array}$ \\
\hline Italy & 33 & 109,500 & 6 & 2 \\
\hline South East Europe & 108 & 285,000 & 10 & 4 \\
\hline United Kingdom & 142 & 405,000 & 7 & 4 \\
\hline France & 28 & 45,000 & 0 & 2 \\
\hline TOTAL & 341 & 984,000 & 23 & 14 \\
\hline
\end{tabular}

\section{Pilot tests of the Preventive Elimination Process of Orange Inventory}

Pilot tests are conducted exclusively in the Western European region to verify their correct functioning before being tested throughout EMOA. It should be noted that in this part of the process are carried out several of the pilot tests in parallel, which saves time of execution.

\section{CONCLUSIONS}

When analyzing the results of the pilot tests of the Redistribution Process, it can be observed that, despite the low familiarity of the employees in this process due to its novelty, results are achieved that have a favorable impact on the IBU and INP indicators. Likewise, the cost of all tests is estimated at 15,750.00 UM, which indicates that for each invested UM, approximately $62 \mathrm{UM}$ of inventory is reduced.

The Finance department states that additional funds can be approved for inventory reduction projects as long as each inverted UM is met, returns $30 \mathrm{UM}$ in reductions. That is, the Redistribution Process is economically feasible and additional resources can be made available for its implementation.

Regarding the pilot tests of the Orange Inventory Preventive Elimination Process, it should be noted that the additional cost to the company in executing this strategy is null, since it allows the early identification of inventories that will potentially become INP in a way to implement the current INP phase-out processes in advance. That is, the expenses for the reduction of the INP will be incurred regardless of whether this process is applied, with the difference that when applied it prevents the impact of INP and IBU indicators.

\section{REFERENCES}

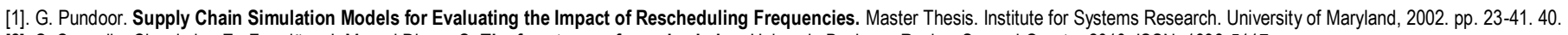

[2]. S. Cannella, Ciancimino E., Framiñan J .M. and Disney S. The four types of supply chains. Universia Business Review Second Quarter 2010. ISSN. 1698-5117.

[3]. Anderson, DL; Britt, FE; Favre, DJ. The Seven Principles of Supply Chain Management, Logistics Management, www.manufacturing.net/magaz. 2015

[4]. Cooper, MC; Lambert, DM; Pagh, JD. Supply Chain Management: More Than a New Name for Logistics. The International Journal of Logistics [1]. Management, 5 (1). 2015. Pp. 45-85.

[5]. Holweg, M .; Disney, SM; Holmström, J .; Småros, J. Supply chain collaboration: making sense of the strategy continuum. European Management Journal, Vol. 23, no. 2. 2015. Pp. 170-181

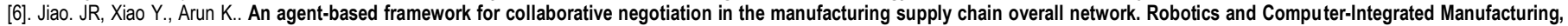
June (2). 2015. pp. 239-255

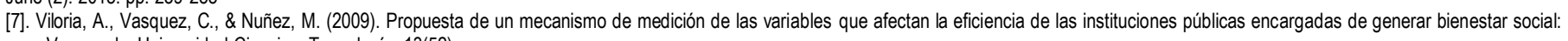
caso Venezuela. Universidad Ciencia y Tecnología, 13(52).

[7]. Viloria, A. (2007). Modelos socioeconómicos para las pymes. Universidad, Ciencia y Tecnología (UCT), 11(42), 39-44

[9]. Torres, M., Vasquez, C., \& Viloria, A. (2010). Gestión y calidad de la información en el gobierno electrónico. Universidad Ciencia y Tecnología, 14(54).

[10]. Viloria, A. (2012). INDICADORES DE GESTIÓN DE LOS PROGRAMAS DE MICROCRÉDITOS. REDIP-Revista Digital de Investigación y Postgrado, 1(3).

[11]. Amelec, V. (2015). Validation process container for distribution of articles for home. Advanced Science Letters, 21(5), 1413-1415.

[12]. Amelec, V. (2015). Validation of strategies to reduce exhausted shelf products in a pharmaceutical chain. Advanced Science Letters, 21(5), $1403-1405$.

[13]. Amelec, V., \& Carmen, V. (2015). Design of a model of evaluation of productivity for microfinance institutions. Advanced Science Letters, 21(5), $1529-1533$.

[14]. Amelec, V., \& Carmen, V. (2015). Validation of a model for productivity evaluation for microfinance institutions. Advanced Science Letters, 21(5), 1610-1614.

[15]. Palencia-Fajardoa, O., Lis-Gutiérrezb, J. P., Gaitán-Anguloc, M., Ariza-Salazard, J., \& Viloriae, A. Competitiness of Clothing SMES in Neiva (Colombia). Small, 11, 50.

[16]. Amelec, V. (2015). Increased efficiency in a company of development of technological solutions in the areas commercial and of consultancy. Advanced Science Letters, 21(5), 1406-1408.

[17]. Amelec, V. (2015). Improvements in the Supply Chain of an Automotive Company Through the Implementation of Continuous Flow. Advanced Science Letters, 21(5), $1416-1418$.

[18]. Amelec, V. (2015). Methodology to increase the adaptability and flexibility of the supply chain of automotive company through lean manufacturing.Advanced Science Letters, 21(5), 1517-1520.

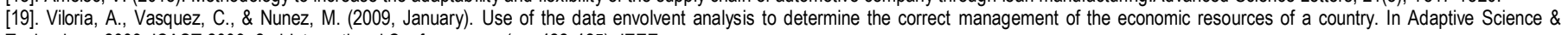
Technology, 2009. ICAST 2009. 2nd International Conference on (pp. 422-425). IEEE.

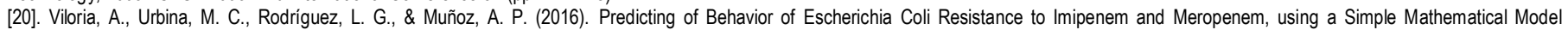
Regression. Indian Journal of Science and Technology, 9(46).

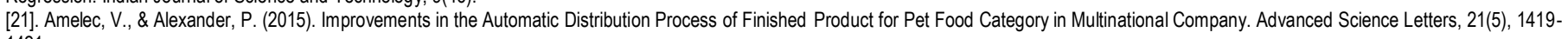
1421.

[22]. Viloria, A., \& Robayo, P. V. (2016). Virtual Network Level of Application Composed IP Networks Connected with Systems-(NETS Peer-to-Peer). Indian Journal of Science and Technology, 9(46).

[23]. Viloria, A., \& Moros, M. A. (2016). Implantation System Brine Recover from Some Chemical Treatment Tanks in a Plant Chlor-Alkali. Indian Journal of Science and Technology, 9(46).

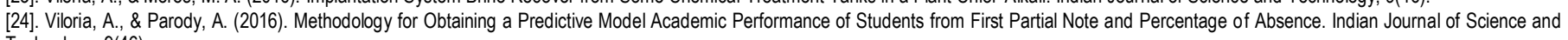
Technology, 9(46).

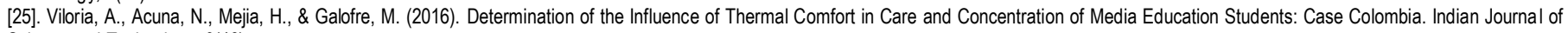
Science and Technology, 9(46). 
[26]. Viloria, A., \& Gaitan-Angulo, M. (2016). Statistical Adjustment Module Advanced Optimizer Planner and SAP Generated the Case of a Food Production Company. Indian Journal of Science and Technology, 8(1).

[27]. Viloria, A., \& Lis-Gutiérrez, J. P. (2016). Focus for Interactive Systems Design through the Incorporation of User in the Development Process. Indian Journal of Science and Technology, 9(46). 